\section{Weak Cough Strength and Secretion Retention in Mechanically Ventilated Patients: Is There a Role for Cough-Assist Devices?}

The article from Camillis et $\mathrm{al}^{1}$ is one of the few studies on mechanically assisted cough for ventilated patients. Considering that the evidence on airway-clearance techniques in this setting is scarce and this device has proven efficacy for out-patients, ${ }^{2}$ we think that this is a relevant contribution. However, the article deserves further comment.

In a controlled, randomized study, the authors observed that the use of the mechanical insufflation-exsufflation device (MI-E) in mechanically ventilated subjects resulted in greater secretion removal than a conventional chest physiotherapy protocol. The authors also found a significant increase in static lung compliance in the MI-E group compared to the conventional chest physiotherapy group (control). Work of breathing and airway-resistance variations were not different between the groups.

Respiratory physiotherapy is not just a matter of removing as much secretion as possible; it also involves being able to move peripheral secretions to more central regions so that they can be eliminated through coughing or suctioning. ${ }^{3}$ In this way, because mechanically ventilated patients are prone to secretion retention ${ }^{4}$ and present with reduced cough peak flow, ${ }^{5}$ cough-assist devices might bring some benefit. Because MI-E mimics a cough, it is likely that the secretions collected after this intervention in the study of Camillis et al $^{1}$ were predominantly from central airways, while in the control group, in which manual hyperinflation was used, may have had a higher effect on the lung periphery. This raises methodological concerns and some questions regarding the interpretation of the results. What were the effects of each intervention on secretion removal from large and small airways? Considering this, if the main outcome measure was recorded $30 \mathrm{~min}$ or $60 \mathrm{~min}$ later, would the results be different? If the subjects had been suctioned immediately before the interventions, would the results be different? What patient populations benefit from MI-E? Far from being simply mechanistic elucubrations, we believe that these questions should be addressed in future studies because the answers may influence the criteria for prescription and application of MI-E in patients on mechanical ventilation. It is also notable that the characteristics of the outcome measures (accuracy, reliability, and sensitivity $)^{6,7}$ and the sample heterogeneity increase the risk of bias in studies on airway-clearance techniques in mechanically ventilated patients. Direct measurements of mucus clearance, like those provided by radiopaque markers, ${ }^{6}$ are difficult to apply in the ICU setting. Thus, the commonly used marker of secretion clearance is the volume or weight of secretions collected after any intervention. For intubated patients, contamination with saliva or swallowing of mobilized secretions are not a concern, but the sputum volume/weight is not sensitive to small differences. ${ }^{6}$ Moreover, as mentioned before, lack of expectoration during physiotherapy treatments does not mean that mucus movement is not happening. ${ }^{7}$

Regarding the risk of selection bias, the amount of secretion and mucociliary clearance may vary among mechanically ventilated patients according to several factors, such as the use of drugs, fluid status, muscle weakness, humidification of respiratory gases, preexisting respiratory conditions, pulmonary infection, or ventilatory settings ${ }^{1,6,7}$ Therefore, most studies on airwayclearance techniques have used a randomized crossover design, where the subjects serve as their own control. ${ }^{8}$ Conversely, in this study, the authors used a 2-arm design. In this case, the randomization may have minimized the between-group differences, but the use of any classification of secretion production at baseline (eg, scarce, if requiring endotracheal suctioning every $4 \mathrm{~h}$ or more; moderate, if requiring suctioning every 2-4 h; or abundant, if requiring suctioning every $2 \mathrm{~h}$ or less ${ }^{9}$ ) would be valuable to select the study participants or as a control variable.

The respiratory mechanics results of this study are difficult to interpret. There is no information on how static lung compliance, airways resistance, and work of breathing were recorded. The hyperinflation provided by the mechanical insufflation-exsufflation device (peak pressure $=40 \mathrm{~cm} \mathrm{H}_{2} \mathrm{O}$ ) may have been responsible for the increase in static compliance. However, although manual hyperinflation was applied in the control group, no improvements in lung compliance and airway resistance were observed. Perhaps the volume delivered during manual hyperventilation was not enough to im- prove the respiratory mechanics in these subjects.

Finally, in the face of the results of this study and the rationale behind cough-assist modalities for intubated patients, we believe that the mechanically assisted cough has therapeutic potential for ventilated patients. It is likely that MI-E is useful for a selected group of patients, such as those with muscle weakness and without airway instability. Nevertheless, before its routine use, more studies are needed to investigate the safety and utility of MI-E for secretion removal from central and peripheral airways, as well as the impact on clinically relevant outcomes, including the incidence of ventilator-associated pneumonia, stay, weaning outcome, and mortality. In addition, because of the need to disconnect the patient from the mechanical ventilator, MI-E may be deleterious for patients at risk of lung collapse (high PEEP levels) or severe hypoxemia. ${ }^{10}$

Fernando S Guimarães PhD PT Physical Therapy Department Federal University of Rio de Janeiro Rio de Janeiro, Brazil

Ângelo RM Rocha PT MSc Physical Therapy Department Helvio Auto Hospital University of Health Sciences Maceió, Brazil

The authors have disclosed no conflicts of interest.

DOI: $10.4187 /$ respcare.06527

\section{REFERENCES}

1. Ferreira de Camillis MC, Savi A, Goulart Rosa R, Figueiredo M, Wickert R, Alegretti Borges LG, et al. Effects of mechanical insufflation-exsufflation on airway mucus clearance among mechanically ventilated ICU subjects. Respir Care 2018; 63(11):1471-1477.

2. Homnick DN. Mechanical insufflation-exsufflation for airway mucus clearance. Respir Care 2007;52(10):1296-1305.

3. Chatwin M, Toussaint M, Gonçalves MR, Sheers N, Mellies U, Gonzales-Bermejo J, Sancho J, et al. Airway clearance techniques in neuromuscular disorders: a state of the art review. Respir Med 2018;136:98-110.

4. Branson RD. Secretion management in the mechanically ventilated patient. Respir Care 2007;52(10):1328-1342.

5. Jiang C, Esquinas A, Mina B. Evaluation of cough peak expiratory flow as a predictor of successful mechanical ventilation discontinuation: a narrative review 


\section{LETTERS}

of the literature. J Intensive Care 2017; 5:33.

6. van der Schans CP. Airway clearance: assessment of techniques. Paediatr Respir Rev 2002;3(2):110-114.

7. Marques A, Bruton A, Barney A. Clinically useful outcome measures for physiotherapy airway clearance techniques: a review. Phys Ther Rev 2006;11(4):299-307.

8. Stoney CM, Johnson LL. Design of clinical trials and studies. In: Gallin JI, Ognibene FP, Johnson LL, editors. Principles and practice of clinical research. Boston: Academic Press; 2018:249-268.

9. Solh AAE, Bhat A, Gunen H, Berbary E. Extubation failure in the elderly. Respir Med 2004;98(7):661-668.

10. Esquinas Rodriguez AM, Pravinkumar E. Mechanical insufflation-exsufflation in prevention of post-extubation acute respiratory failure: most welcome but must be used cautiously in critically ill patients (letter). Crit Care 2012;16(3):431.

\section{Mechanical Insufflation- \\ Exsufflation Is Safe in Mechanically Ventilated Patients}

\section{In Reply:}

We thank Guimarães and Rocha for their interest and comments regarding our study, ${ }^{1}$ as well as the suggestions and doubts they advance. We have a few comments regarding their concerns. We believe it is important to emphasize that our objectives were to determine the safety of mechanical insufflation-exsufflation in mechanically ventilated, critically ill subjects, and to determine the efficacy of the device in the removal of respiratory secretions compared to standard physiotherapy.

Our colleagues questioned some aspects of the study, which we will respond to here. They suggest that secretion removal occurred predominantly from central airways, and we agree with this statement; however, we emphasize that this is the main objective of the maneuvers for respiratory secretion removal. ${ }^{2,3}$ It is impossible to know how long the effect of the maneuver may last
(30 min or $4 \mathrm{~h}$ ), but it is reasonable to suggest that it follows the performance already demonstrated in patients with chronic neuromuscular disease. Because the hyperinflation technique was applied as part of routine patient care, there were no pressure or volume measurements during hyperinflation, and therefore it is not possible to affirm that this would displace more peripheral secretions than the $40 \mathrm{~cm} \mathrm{H}_{2} \mathrm{O}$ pressure exerted by mechanical insufflationexsufflation. The technique of manual hyperinflation and thoracic compression were chosen for the control group because these techniques are used to remove secretions in intubated patients with some reports of success in the literature. ${ }^{2-4}$

We agree with Guimarães and Rocha that the heterogeneity of individuals may generate bias in studies measuring the quantity of secretions; however, as shown in Table 1 of our report, ${ }^{1}$ both groups show homogeneity for previous pathologies, comorbidities, and other factors, reducing the possibility of selection bias. The randomized clinical trial design was chosen to reduce the possibility of bias, especially with the sample size of 180 subjects, which was based on findings with the same design in a smaller sample size. ${ }^{5}$ As for the method used to quantify the amount of secretions, weighing secretions is a commonly used technique in the literature.6,7

We again thank the authors for commenting on our study ${ }^{1}$ and their thoughtful suggestions. The main focus of our work was to verify the amount of secretions and to determine whether mechanical insufflationexsufflation could be a useful airway-clearance technique in critically ill patients. Future studies should certainly be performed to assess outcomes such as days on mechanical ventilation, incidence of ventilator-associated pneumonia, and ICU mortality.

Márcio Luiz Ferreira de Camillis PT
Cassiano Teixeira MD PhD
Regis Goulart Rosa MD PhD Intensive Care Unit
Hospital Moinhos de Vento Porto Alegre, Brazil

The authors have disclosed no conflicts of interest.

DOI: $10.4187 /$ respcare. 06575

\section{REFERENCES}

1. Ferreira de Camillis MC, Savi A, Goulart Rosa R, Figueiredo M, Wickert R, Alegretti Borges LG, et al. Effects of mechanical insufflation-exsufflation on airway mucus clearance among mechanically ventilated ICU subjects. Respir Care 2018; 63(11):1471-1477.

2. Moreira FC, Teixeira C, Savi A, Xavier R. Changes in respiratory mechanics during respiratory physiotherapy in mechanically ventilated subjects. Rev Bras Ter Intensiva 2015; 27(2):155-160.

3. Naue Wda S, Forgiarini Junior LA, Dias AS, Vieira SR. Chest compression with a higher level of pressure support ventilation: effects on secretion removal, hemodynamics, and respiratory mechanics in patients on mechanical ventilation. J Bras Pneumol 2014;40(1): 55-60.

4. Goni Viguria R, Yoldi-Arzoz E, CasajusSola L, Aquerreta-Larraya T, FernandezSangil P, Guzman-Unamuno E, MoyanoBernardo BM. Respiratory physiotherapy in intensive care unit: bibliographic review. Enferm Intensiva 2018;29(3):10-14.

5. Siriwat R, Deerojanawong J, Sritippayawan S, Hantragool S, Cheanprapai P. Mechanical insufflation-exsufflation versus conventional chest physiotherapy in children with cerebral palsy. Respir Care 2018;63(2): 187-193.

6. Dias CM, Siqueira TM, Faccio TR, Gontijo LC, Salge JA, Volpe MS. Bronchial hygiene technique with manual hyperinflation and thoracic compression: effectiveness and safety. Rev Bras Ter Intensiva 2011;23(2): 190-198.

7. Dennis D, Jacob W, Budgeon C. Ventilator versus manual hyperinflation in clearing sputum in ventilated intensive care unit patients. Anaesth Intensive Care 2012; 40(1):142-149. 